ORIENTAL JOURNAL OF
ISSN: 0974-6471
June 2017,
$\begin{gathered}\text { Col. 10, No. (2): } \\ \text { Pgs. 291-297 }\end{gathered}$
$\begin{gathered}\text { An International Open Free Access, Peer Reviewed Research Journal } \\ \text { Published By: Oriental Scientific Publishing Co., India. } \\ \text { www.computerscijournal.org }\end{gathered}$

\title{
Impact of Biometric Attendance System on Secondary and HigherSecondary Educational Institutions Across J\&K.
}

\author{
MUDASIR M KIRMANI \\ Computer Science, Sher-e-Kashmir University of Agricultural Sciences \& \\ Technology of Kashmir Srinagar, J\&K, India. \\ Corresponding author Email: mmkirmani@gmail.com \\ http://dx.doi.org/10.13005/ojcst/10.02.06
}

(Received: May 19, 2017; Accepted: May 25, 2017)

\begin{abstract}
Managing and monitoring attendance of employees is very important aspect for smooth functioning of any public or private organization. To obtain and maintain the attendance of employees in an organization has become a challenging aspect to deal with. In order to avoid human bias and direct human intervention different government institutions have implemented Biometric attendance system in educational institutions to record employee attendance on daily basis. This research work aims to study the impact of Biometric Attendance system(BAS) on educational system vis-a-vis punctuality of employees in an educational institute. The study indicates that biometric modalities are universally secure and accurate, but in practice the scenarios of attendance systems in Jammu \& Kashmir has highlighted some loopholes which are existing at present in the Biometric attendance system.
\end{abstract}

Keywords: Biometrics, Fingerprint, Biometric attendance system, Fingerprint identification and authentication.

\section{INTRODUCTION}

Attendance is very indispensable aspect in any organization, small or big, public or private. Attendance is the main tool to monitor the punctuality of employees in any organization. The punctuality of employee is directly proportional to the discipline of an organization which results in better management of the processes within an organization. There have been different strategies to record attendance of both staff and students in schools across India'. In the existing literature both token and knowledge based; wired or wireless attendance systems are present and these systems have been implemented at different places across the globe ${ }^{2,3}$. The government of Jammu \& Kashmir has initiated the process to install Biometric attendance devices in various departments across the state. However, health and education are the mostly discussed departments wherein the biometric attendance system has been installed in earlier phases during the implementation. 
Prior to the implementation of Biometric Attendance System, a manual system was used by every department of the state to acquire attendance of the employees in education department. The teaching as well as non-teaching employees of the education department were used to maintain the record of their respective attendance by putting their signatures in the attendance register. A record book usually called as "arrival book" was the main record keeping register for acquiring attendance at different units of the education department. The entries in "arrival book" were usually made on the basis of seniority or designation within a unit. Each entry in this "arrival book" had a serial number followed by name and signature of the employee. The first serial number of the attendance sheet in arrival book was assigned to the head of the unit or institution. This traditional method involved the use of books/registers in maintaining the attendance and the information about the attendance was forwarded to the accounts department for process of salary on monthly basis.

This method could easily allow for impersonation and the attendance book could be easily stolen or lost. This traditional system provides an employee with the chance to sign into it across the day and in certain cases the personal approach of any employee with the head of institution can mark his attendance easily and he/she can either sign in advance or even on the days when the person was actually off the records. Keeping these facts in mind the need of the hour is to implement Biometric Attendance System in letter and spirit which will result in mitigating the bias within an organization or a government department.

Biometric Attendance System is proposed as a solution to overcome the challenges being faced by administration emerging from the traditional system. The inception of this modularity was quite anticipatory but as time progressed this system also begins to show its loopholes. One of the possible loopholes from BAS can be reduction in interaction between the head of the institution and subordinates based on the attendance as the subordinates are not required to visit the office for putting their signature rather they have to visit the biometric device. In this paper the main objective of the study will remain confined to Biometric
Attendance System and its implementation in Educational institutions of Jammu and Kashmir.

\section{Biometrics}

Biometrics is the Greek word consisting of two terms, bio and metrics. Bio means life and metrics means measurement. Biometric system means that the system is based on Physiological or behavioural characteristics wherein the specific metrics are treated as the specimen to act as a token to claim individuality. Physiological characteristics include hand or finger images, facial characteristics, gait, palm geometry and IRIS recognition. Behavioural characteristics are traits that are learned or acquired like Dynamic Signature Verification, Voice Verification, and Keystroke Dynamics.

Biometric system begins with the identification of a particular human trait to make that as a token to be used for identification and verification of an individual in a system. The popularity of these biometric systems is because of their characteristic like their universality, individuality, security, accurracy and reliability. There are number of biometric characteristics that have been identified and used in different systems as a mechanism to secure the valuable assets. The most popular and most frequently used ones are: fingerprints, face recognition, IRIS scanning, retina recognition, hand and finger geometry, gait, voice recognition and signature[4]. All these types take their respective biometric template or trait as the token to be captured and later subjected for verification to perform match.

\section{Fingerprints}

Fingerprints are the most popular and most commonly used biometric model to build security mechanism to safeguard valuable assets from being illegally accessed by malicious users. Fingerprints are unique to every individual even twins have different fingerprint patterns. The patterns of ridges and valleys on an individual's fingertips constitute individual fingerprint. The pattern of these ridges, their bifurcation, interception on ones fingertips are extracted by following a systematic biometric fingerprint extraction method. These extracted fingerprint patterns are called as minutiae. These minutiae are latter treated with 
different processes to remove false minutiae or noise to store more accurate one in the database for identification and verification of any individual.

Fingerprint systems can also be used in identification mode. Several states check fingerprints for new applicants to social services benefits to ensure recipients do not fraudulently obtain benefits under fake names ${ }^{5}$. The ubiquity of biometric fingerprint identification system has made it very much popular which has resulted in acceptance of this system in more number of organization as a security measure to ensure individual authenticity.

\section{Biometric Attendance system}

Biometric Attendance System BAS is a software which manages the huge data related to the attendance of different employees within an organization or institution. This software acts as a mediator between the biometric device and the end user. The end user can be any employee from the institution who will be required to user appropriate user-ID and password to login to the BAS software. As an administrator the employee can make appropriate entries related to outdoor entries, leaves, holidays as per the policies of the institution or organization. The BAS will help the administrator to manage the biometric devices online and will ensure that the attendance of the employees within the institution is updated in order to generate reports about the employees attendance which can be submitted to the administrative heads for monitoring and management of an institution or organization.

The biometric attendance system begins its operation from enrolling the sample form an employee who is part of the particular institution or organization. To enroll the fingerprint of the employee the operator of the system lets the employee to place his/her finger on the biometric sensor. Biometric sensor captures and scans the whole fingerprint of the individual employees fingertip. The process is repeated to three times for an employee during the enrollment process. The obtained fingerprint is later preprocessed to enhance the fingerprint image quality and removing any deformity or noise which sometimes happens to be associated with the captured sample. Image binarization and segmentation is performed to confine the boundaries for the sample to be stored in sample pool. Once the captured sample is enhanced and segmented the actual process of extract the exact fingerprint called as minutiae[7] is stored in the biometric device. To ensure that the extracted minutiae is accurate and noise free, the minutiae is subjected to thinning process in which some edges which are considered to be part of noise are removed from the minutiae [8][9]. After all these operation on the biometric fingerprint is performed to ensure the noise free minutiae, the minutiae is stored in template database for latter verification and validation of a particulate employee.

All the employees are first required to enroll their fingerprint and this is stored in the local system (i.e Biometric Device). After completion of the process of enrollment on the Biometric Device an employee has to place his finger on the sensor of the Biometric device to mark his/her attendance. Sensor scans the fingerprint to extract the relevant minutiae. This scanned information is matched with the minutiae stored in the biometric device. One the match is performed successfully the attendance of the employee is marked as present with the exact date and time of the finger scanning on the biometric device. The marked attendance is then updated to the BAS Biometric attendance system which can be stationed at a centralized location based on the feasibility of an organization.

Biometric attendance system consists a series of process right from enrolling the fingerprint to validation and verification of the scanned fingerprint. These different processes are described in figure 1.

Biometric fingerprint attendance system or simply biometric attendance system broadly reforms two main operations discussed below

\section{Enrolling Employees Fingerprint}

All the employees whom are part the institution are required to enroll their fingerprint, They are made aware that this fingerprint is now their signature to entertain their daily attendance they used to perform on book on daily basis. The scanned fingerprint if detected perfectly by biometric device is automatically stored in system. The same 
operation is repeated for all the employees during the enrolment phase. The biometric system the employee to capture fingerprint of both the hands.

\section{Entertain Fingerprint to Enroll Attendance}

Once the enrollment process of the fingerprints is completed for all the employees in the school, it can switch over to the BAS. The attendance on this biometric system is performed by scanning the finger over the sensor which is placed in operator room. The scanned fingerprint is automatically validated and verified by biometric attendance system to check whether there is existing match in database or not. If there fingerprint scanned from the employee is accurate and has match in database the attendance is automatically enrolled. the same procedure is repeated everyday to update the attendance. The biometric attendance system in schools of Jammu \& Kashmir has two phased attendance marking process where an employee needs to swipe his/her finger at entry time and at exit time. The attendance of all employees within a school of institution is updated on the BAS on regular basis automatically.

To mitigate the impact of mismanagement and favoritism among the employees and to ensure smooth functioning of academic institutions within the state of Jammu \& Kashmir, the state government has started an initiative to switch from traditional system of attendance management to biometric attendance system. In biometric attendance systems employees can easily make their attendance by just scanning their finger over the biometric scanner or sensor. There is no personal intervention or favoritism as was cited in traditional system. Biometric attendance system is installed in most of the school (secondary and higher secondary level) in Jammu \& Kashmir. However, the process of switching over will take more time to cover all the educational institutions within the state.

\section{Acceptability of Biometric Attendance System}

As employees in schools were fond of using traditional book based attendance system. The implementation of this new automated attendance system has been a difficult process for the implementation agencies as well as administrative authorities Employees were not aware of this technology and they felt it mundane to manage. The employees had a feeling of insecurity and were concerned about the privacy of the data about an employee. After appropriate awareness within institution by administrative authorities slowly and gradually the acceptance among the employees is increasing with every passing day. The ease-ofuse feature of BAS has motivated administrative authorities to use the BAS holistically keeping in mind the benefits of monitoring the attendance any time any where based on the connectivity with BAS.

\section{Challenges of Biometric Attendance System}

The BAS system is secure and there are lesser chances of tempering the information stores and the influence of bias is less. However, the performance of the biometric devices in tandem with BAS need to be monitored for errors and issues which may pitch in from time to time and

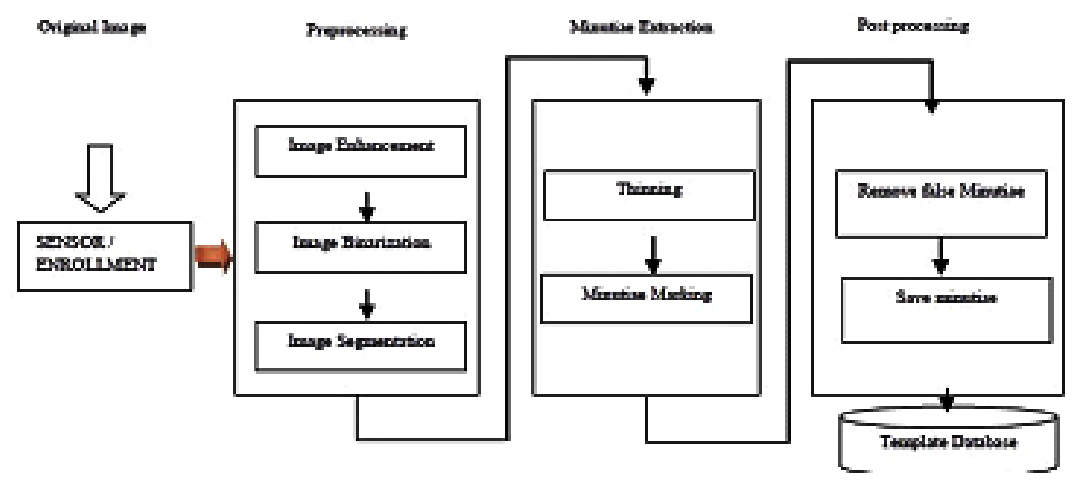

Fig. 1: Finger print scan and storage in BAS [6] 
the authorities have to ensure timely fixation of the errors or issues related to BAS. The operational aspect of the biometric attendance system makes it very challenging and to address these challenges is an important task that administrative authorities have to take care off.

Biometric sensors are programmed to accept fingerprints at entry time for example 10 $\mathrm{AM}$ and the acceptance window will remain open for half an hour after that the entry time is closed. In the same pattern the exit window begins at say 4PM and remains from half an hour prior to the exit time. If an employee marks his/her attendance after 10:30 in the morning he will marked late and similarly if an employee leaves earlier (i.e before $3: 30)$ then the attendance will be marked as "The employee has left early". In case an employee marks his exit attendance at 1:00 PM the BAS will automatically calculate that the employee has left after half day working and he/ she will be treated on half day leave.

In order to find out the challenges that BAS has to address, different interaction were carried out with all the stake holders of different institutions and the outputs obtained are briefly summarized below:

There is no doubt in the punctuality of signature of the employee, but there is no surety that the swipe was made organically by same employee. The Biometric System in place makes it to accept fingerprints from both hands. If their happens to be some personal influence with the administrator of BAS, there is chance that two persons can enroll their fingers for one person and in the absence of an employee someone else from the same organization can swipe his finger. This is possible only when the operator/ administrator of BAS has allowed this at the time of enrollment of employees.

This is no confusion that this system ensures that the employee has marked the attendance at appropriate time in the morning as well as evening session. However, the BAS cannot ensure the employees presence in the institution.
This system has created a situation where employees are very serious about the entry and exit timings as they are supposed to mark the attendance which can result in deviation from official assignments.

As the system is not remotely monitored by any officials, employees hardly care about the attendance if they have good relationship with the operator or head. The attendance can easily be updated by operator even when employee was actually off the records.

The BAS may ensure the attendance of the employees within an educational institution but it cannot contribute towards the betterment of quality education.

Keeping the paucity of funds, some of the institutions find it difficult to manage funds to acquire IT infrastructure and other ICT tools to enable proper connectivity of BAS with biometric devices.

Continuous electricity supply at different educational institutions in remote location within the state is an issue of concern.

Less acceptance of the BAS by the stakeholders of an educational institution.

\section{Proposed guidelines for better Biometric attendance system}

As Govt. of Jammu and Kashmir has already spend a good budget on implementation of Biometric attendance system. To ensure its positive and productive effect on the academics there is a scope for its further enhancement:

1. Instead of enrolling fingerprint scans from both hands it will better to use multimodal biometric setup. Multimodal Biometric setup will be more secure and reliable.

2. Before installing the biometric setup, ensure that the school has sufficient power supply to cater power consumption requirements of Biometric Attendance System.

3. Ensure that the operator have only read and execute rights and no right to modify the 
biometric device entries on BAS.

4. The operator should not be allowing to mark attendance of an employee using the manual option on BAS.

5. The operator shout not mark any outdoor entries or leave entries without the approval of administrative authorities.

6. The BAS Biometric Attendance Systems needs to be monitored from centralized remote monitoring agency to ensure more security in the system.

7. to ensure the presence of the employee in between entry and exit window, each employee may be provided with Identity-cards having RFID identifier facility. To trace the malicious or proxy attempt by employee by placing the card within campus to avoid unusual alarm GPS monitoring of RFID may to be monitored. [10][11].

8. Awareness about the advantages of using BAS.

\section{CONCLUSION}

Maintaining attendance regularly is very important to create better environment for quality education in schools. There were some issues that administrative authorities had to face while using traditional book based attendance system. The scope for biased attendance was more in traditional attendance system. To avoid and curtail this challenges a more reliable and secure attendance system like Biometric Attendance System was introduced in education institutions across the state of Jammu \& Kashmir. The BAS has pros and corns based on the research work carried out in different educational institutions within the state. However, it is important to implement the BAS with proper planning and availability of funds. The BAS helps the administrative authorities to monitor the employees attendance effectively and efficiently. The study can be further extended to analyze the impact on health department of the state. The Impact of BAS on the performance of the employees at the same time also needs to studied.

\section{REFERENCES}

1. Shoewu, O, O.M. Olaniyi, and A. Lawson. 2011. "Embedded Computer-Based Lecture Attendance Management System". African Journal of Computing and ICT (Journal of IEEE Nigeria Computer Section). 4(3):27 36.

2. Kadry, S. and M. Smaili. 2010. "Wireless Attendance Management System Based on Iris Recognition".

3. Cheng, K., L. Xiang, T. Hirota, and K. Ushijimaa. 2005. "Effective Teaching for Large Classes with Rental PCs by Web System WTS". Pro. Data Engineering Workshop (DEWS2005), 1D - d3 (in Japanese).

4. Whitman, Michael E. and Mattord, Herbert J. Management of Information Security. Boston, Massachusetts: Thomson Course Technology, 2004, 363-375

5. Robert Carrigan, Ron Milton, Dan Morrow, "Automated fingerprint identification systems", Technical Report by Computer world donors case study, 2005.
6. Syed Mohsin Saif et al ., Effectiveness Of Gaussian And Average Noise Reduction Filters On Ideal Fingerprint Image In Biometric Fingerprint Identification System. International Journal of Recent Scientific Research Vol. 6, Issue, 8, pp.5731-5736, August, 2015

7. Hong, L, Wan, $Y$ and Jain, A.K.'Fingerprint image enhancement: Algorithm and performance evaluation", IEEE transactions on Pattern Analysis and Machine Intelligence 20, 8(1998),777-789.

8. Saraswat, C. et al. 2010. "An Efficient Automatic Attendance System using Fingerprint Verification Technique". International Journal on Computer Science and Engineering. 2(02):264-269.

9. Maltoni, D., D. Maio, A.K. Jainl, and S. Prabhaker. 2003. Handbook of Fingerprint Recognition. Springer- Verlag: Berlin, Germany.

10. Pankanti, S., S. Prabhakar, and A.K. Jain. 2002. "On the Individuality of Fingerprints". 
IEEE Transaction on Pattern Analysis and Machine Intelligence. 24(8).

11. Shoewu, O. and O. Badejo. 2006. "Radio Frequency Identification Technology:
Development, Application and Security Issues". Pacific Journal of Science and Technology. 7(2):144-152. 